\title{
Development of a Scattering Model for Soybean Fields and Verification with Scatterometer and SAR Data at X-Band
}

\author{
Soon-Koo Kweon · Ji-Hwan Hwang $\cdot$ Yisok Oh
}

\begin{abstract}
This paper presents a scattering model and measurements of backscattering coefficients for soybean fields. The polarimetric radar backscatters of a soybean field were measured using the ground-based X-band polarimetric scatterometer in an angular range from $20^{\circ}$ to $60^{\circ}$. The backscattering coefficients were also obtained using the COSMOSkyMed (Spotlight mode, HH-polarization) from July to October 2010. The backscattering coefficients of the soybean field were computed using the 1st-order radiative transfer model (RTM) with field-measured input parameters. The soybean layer is composed of the stems, branches, leaves, and soybean pods. The stems, branches, and pods are modeled with lossy dielectric cylinders, the leaves are modeled with lossy dielectric disks. The estimated backscattering coefficients agree quite well with the field-measured radar backscattering coefficients.
\end{abstract}

Key words: Vegetation Canopy, Backscattering Coefficients, Radiative Transfer Model, Soybean Field, SAR.

\section{Introduction}

Remote sensing of earth surfaces using synthetic aperture radar (SAR) has been extensively studied over the past several decades. Today, many scattering models are available for analyzing the radar backscattering coefficients of bare soil surfaces, sea surfaces, forests, agricultural fields, etc [1]. Many scattering models have been developed for bare surfaces, and the accuracy of these models has been validated by radar measurements [2]. However, until now, even though many studies have been done on vegetated surfaces, the accuracy of the scattering models for these types of surfaces still remains to be validated. The Radiative transfer model (RTM) is one of the best-known scattering models for the vegetation layer [3]. In RTM, the backscattering coefficients are calculated using five basic scattering mechanisms between the layers [4]. The accuracy of the scattering matrix of each particle is therefore a key factor for determining the total backscattering coefficient. Thin disks are used for leaves, and cylinders for branches, stems, and bean pods.

In the present study, we developed a scattering model for microwave scattering from a vegetation canopy, which shows a reasonably good accuracy. This model employs the iterative vector radiative transfer theory to compute the backscattering coefficients, including the first-order multiple scattering effects.

\section{Scattering Model}

This scattering model is based on the 1st-order RTM. In 1st-order RTM, the backscattering coefficient is comprised of five mechanisms between the ground and vegetation layer. Five scattering mechanisms consist of direct vegetation scattering, direct ground scattering, vegetation-ground scattering, ground-vegetation scattering, and ground-vegetation-ground scattering. Ground scattering is calculated by using $\mathrm{Oh}$ et al.'s model [5]. Oh model is one of the best-known ground scattering models for bare soil. Particles of the vegetation layer are calculated by using the physical optics (PO) technique for stems, branches, leaves, and soybean pods [1], [6]. The number of input parameters for the scattering model is about 40 except radar parameters (frequency, incidence angle, and polarization).

The backscattering coefficients of a vegetated surface are obtained from the $4 \times 4$ transformation matrix $\overline{\bar{T}}$ which can be computed using the extinction matrices of the vegetation canopy, the reflectivity matrix of the ground surface, and scattering-mechanism matrices corresponding to five scattering mechanisms [7]. Backscattering coefficients are computed using the transformation matrix as in the following equation.

$$
\begin{aligned}
& \sigma_{p q}^{o}=4 \pi \cos \theta_{0} \overline{\bar{T}}_{t, p q} \\
& \overline{\bar{T}}_{t}=\overline{\bar{T}}_{c}+\overline{\bar{T}}_{g}
\end{aligned}
$$

where $\overline{\bar{T}}_{c}$ is the transformation matrix relating vegeta-

Manuscript received September 26, 2011 ; Revised January 18, 2012 ; Accepted February 8, 2012. (ID No. 20110926-02J)

Dept. of Electronic Information \& Communication Engineering, Hongik University, Seoul, Korea.

Corresponding Author : Yisok Oh (e-mail : yisokoh@hongik.ac.kr)

This is an Open-Access article distributed under the terms of the Creative Commons Attribution Non-Commercial License (http:/creativecommons.org/licenses/ by-nc/3.0) which permits unrestricted non-commercial use, distribution, and reproduction in any medium, provided the original work is properly cited. 
tion canopy and $\overline{\bar{T}}$ is the transformation matrix for the direct backscatter from the ground surface. In case of the radar backscatter, the expression for $\overline{\bar{T}}_{c}$ is given by

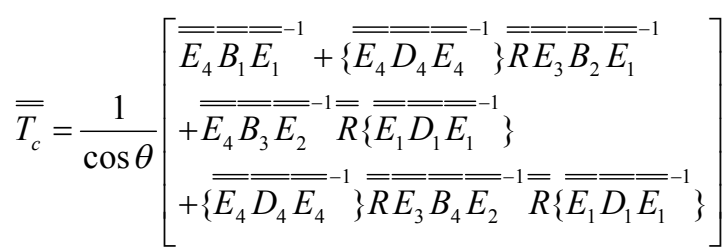

where $\overline{\bar{E}}$ is the eigenmatrix which can be expressed by Mueller matrix parameters, $\overline{\bar{D}}$ is a diagonal matrix, and $\overline{\bar{R}}$ is the reflectivity matrix. $\overline{\bar{E}}$ and $\overline{\bar{D}}$ matrix are composed with $2 \times 2$ matrix which can be expressed by

$$
\overline{\overline{M_{j}}}=\frac{-j 2 \pi}{k_{0}}\left[N_{s}\left\langle\overline{\overline{S_{s}}}\right\rangle+N_{b}\left\langle\overline{\overline{S_{b}}}\right\rangle+N_{b n}\left\langle\overline{\overline{S_{b n}}}\right\rangle+N_{l}\left\langle\overline{\overline{S_{l}}}\right\rangle\right]
$$

where $N_{s}, N_{b}, N_{l}$ and $N_{b n}$ are the number densities per unit volume of stems, branches, leaves, and soybean pods, respectively. $\overline{\overline{S_{k}}}$ is the forward scattering matrices of particle k. Subscripts represent propagation directions; i.e., subscript 1 for 'incidence to downward' $(\searrow$ ), subscript 2 for 'scattering to upward' $(\nearrow)$, subscript 3 for 'incidence to downward' $(\swarrow)$, and subscript 4 for 'scattering to upward' $(\backslash)$. The four scattering terms of $\overline{\overline{B_{1}}}, \overline{\overline{B_{2}}}, \overline{\overline{B_{3}}}$ and $\overline{\overline{B_{4}}}$ represent mechanisms (1), (2), (3), and (4) respectively, as shown in Fig. 1. $\overline{\overline{B_{j}}}$ are expressed by

$$
\begin{aligned}
& \overline{\overline{B_{1}}}={\overline{\overline{E_{4}}}}^{-1} \overline{\overline{P_{41}}} \overline{\overline{E_{1}}} C_{1} \\
& \overline{\overline{B_{2}}}={\overline{\overline{E_{3}}}}^{-1} \overline{\overline{P_{31}}} \overline{\overline{E_{1}}} C_{2} \\
& \overline{\overline{B_{3}}}={\overline{\overline{E_{4}}}}^{-1} \overline{\overline{P_{42}}} \overline{\overline{E_{2}}} C_{3} \\
& \overline{\overline{B_{4}}}={\overline{\overline{E_{3}}}}^{-1} \overline{\overline{P_{32}}} \overline{\overline{E_{2}}} C_{4}
\end{aligned}
$$

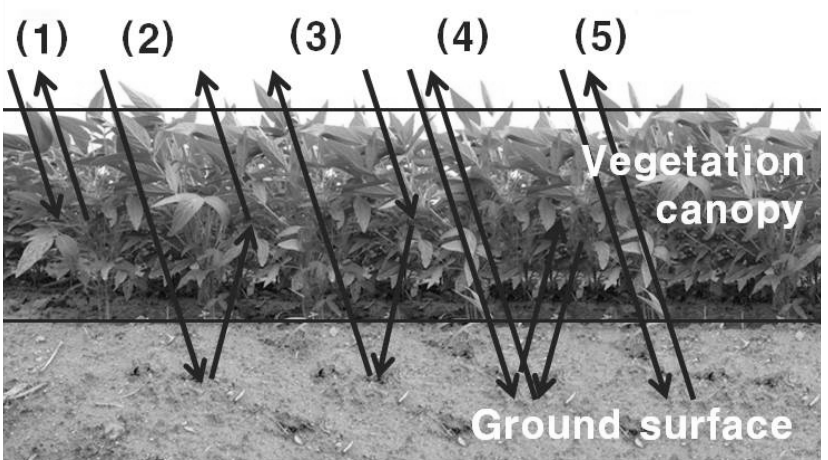

Fig. 1. Scattering mechanisms of the 1st-order RTM. where $\overline{\bar{P}}$ is the phase matrix which can be computed by integration of the Mueller matrix $\overline{\bar{M}}$ multiplied by the distribution functions of the scattering particles.

$$
\overline{\overline{P_{i j}}}=N_{s}\left\langle\overline{\overline{L_{s}}}\right\rangle_{i j}+N_{b}\left\langle\overline{\overline{L_{b}}}\right\rangle_{i j}+N_{b n}\left\langle\overline{\overline{L_{b n}}}\right\rangle_{i j}+N_{l}\left\langle\overline{\overline{L_{l}}}\right\rangle_{i j}
$$

where $\langle\overline{\bar{L}}\rangle$ is ensemble average of Mueller matrix $\overline{\bar{L}}$ of each particles. For example, in the case of stems, branches, and pods are counted as cylindrical shapes. Therefore, length $l$, diameter $a$, and parameter $\theta_{j}, \phi_{j}$ that is the represented orientation considered for averaging. The ensemble average of the cylindrical shape is expressed by

$$
\langle\overline{\bar{L}}\rangle=\int_{\phi_{j}} \int_{\theta_{j}} \int_{l} \int_{a} \overline{\bar{L}}\left(a, l, \theta_{j}, \phi_{j}\right) P\left(a, l, \theta_{j}, \phi_{j}\right) d a d l d \theta_{j} d \phi_{j}
$$

where $\overline{\bar{L}}_{s}, \overline{\bar{L}}_{b}, \overline{\bar{L}}_{b n}$, and $\overline{\bar{L}}_{l}$ relates the incident and scattered intensities for a single particle and $P$ is the joint probability density function. $C$ is given as in (8).

$$
C_{i j}=\int_{-d}^{0} e^{-\beta_{i}\left(\pi-\theta_{s}, \phi_{s}\right)\left(d+z^{\prime}\right) \sec \theta_{s}} e^{-\beta_{j}\left(\pi-\theta_{0}, \phi_{i}\right) \sec \theta} d z^{\prime}
$$

The $4 \times 4$ Mueller matrices are calculated using the scattering matrices $\overline{\bar{S}}$ of scatterers. The expression for $\overline{\overline{T_{g}}}$ is given by

$$
\overline{\overline{T_{g}}}=\frac{1}{\cos \theta}\left[\overline{\overline{M_{4}}} \overline{\overline{M_{m}}} \overline{\overline{M_{1}}}\right]
$$

where $\overline{\overline{M_{m}}}$ is the modified Stokes scattering operator, which describes the ground backscatter. The $4 \times 4$ matrix elements can be computed by the polarimetric empirical model (PEM) presented by $\mathrm{Oh}$ et al. in (10).

$$
\begin{aligned}
& \sigma_{v h}^{0}=0.11 M_{v}^{0.7}(\cos \theta)^{2.2}\left[1-e^{-0.32(k s)^{1.8}}\right] \\
& p=\frac{\sigma_{h h}^{0}}{\sigma_{v v}^{0}}=1-\left(\frac{\theta}{90}\right)^{0.35 M_{v}^{0.65}} \cdot e^{-0.4(k s)^{1.4}} \\
& q=\frac{\sigma_{v h}^{0}}{\sigma_{v v}^{0}}=0.1\left(\frac{s}{l}+\sin 1.3 \theta\right)^{1.2}\left(1-e^{-0.9(k s)^{0.8}}\right) \\
& \alpha=1-\left(17+0.01 k l+0.5 M_{v}\right) \cdot(\sin \theta)^{1.1 .(k s)^{-0.4}} \\
& \varsigma=\left(0.44+0.95 M_{v}-\frac{s}{l}\right) \theta
\end{aligned}
$$

where $s$ is surface RMS height, $l$ is surface correlation length and $k$ is the wavenumber. Here, $\alpha$ is the degree 


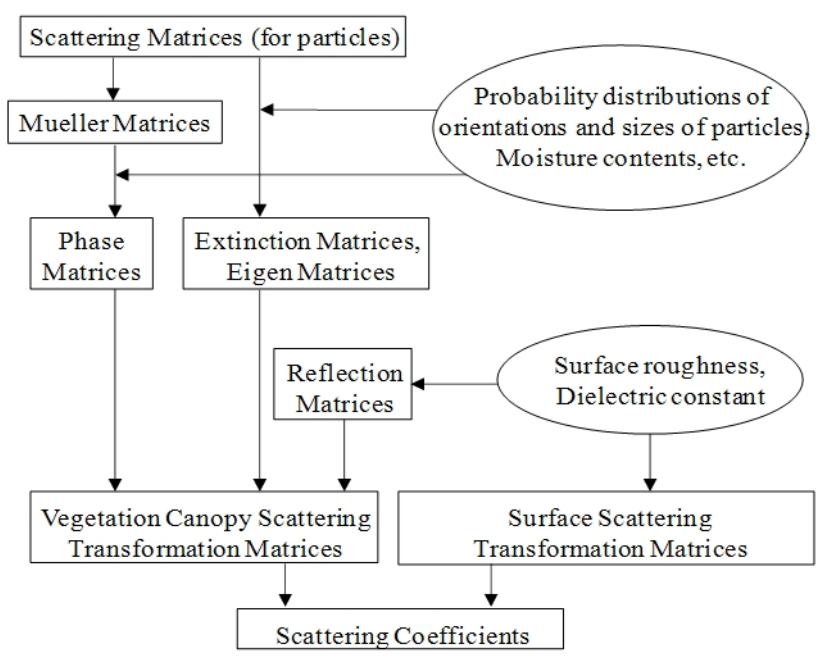

Fig. 2. Flowchart for the radiative transfer technique.

of correlation and $S$ is the co-polarized phase-difference [5]. The block diagram shown in Fig. 2 shows the RTM procedure.

The major input parameters of this scattering model are canopy height $(\mathrm{cm})$, stem density $\left(\mathrm{m}^{-2}\right)$, stem water content $\left(\mathrm{g} / \mathrm{cm}^{3}\right)$, stem diameter $(\mathrm{cm})$, stem length $(\mathrm{cm})$, stem vertical angle $(\mathrm{deg})$, branch density $\left(\mathrm{m}^{-2}\right)$, branch water content $\left(\mathrm{g} / \mathrm{cm}^{3}\right)$, branch diameter $(\mathrm{cm})$, branch length $(\mathrm{cm})$, branch vertical angle (degree), leaf density $\left(\mathrm{m}^{-2}\right)$, leaf water content $\left(\mathrm{g} / \mathrm{cm}^{3}\right)$, leaf width $(\mathrm{cm})$, leaf length $(\mathrm{cm})$, leaf thickness $(\mathrm{cm})$, leaf vertical angle (degree), soybean pod density $\left(\mathrm{m}^{-2}\right)$, soybean pod water content $\left(\mathrm{g} / \mathrm{cm}^{3}\right)$, soybean pod width $(\mathrm{cm})$, soybean pod length $(\mathrm{cm})$, soybean pod thickness $(\mathrm{cm})$, surface soil moisture $\left(\mathrm{cm}^{3} / \mathrm{cm}^{3}\right)$, surface RMS height $(\mathrm{cm})$ and surface correlation length $(\mathrm{cm})$.

\section{Measurements}

The results of the 1st-order RTM simulation are compared with the measured backscattering coefficients to verify the scattering model. The backscattering coefficients are obtained using eleven COSMO-SkyMed images (Spotlight mode, HH-polarization) at 30 and 40 degrees from July to October 2010. Fig. 3 shows the COSMO-SkyMed SAR image of the area of Suwon, Korea.

The backscattering coefficients of a soybean field have been also measured using the well calibrated ground-based X-band polarimetric scatterometer system (HPS: Hongik Polarimetric Scatterometer) at $9.65 \mathrm{GHz}$ and full-polarizations in 2010 [8]. Fig. 4 shows the scatterometer system which consists of a vector network analyzer, an antenna support for automatically controlling azimuth and elevation angles, and an X-band sub-circuit for an X-band operation. We also collected ground truth data for measuring the input parameters of the scattering

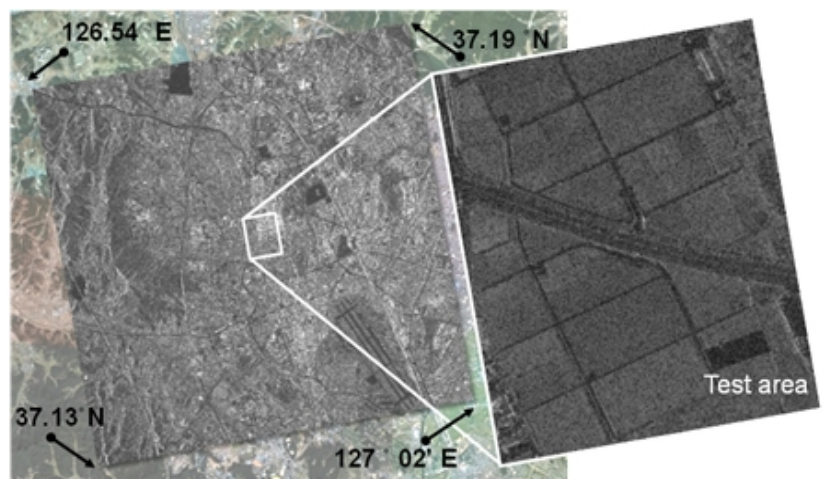

Fig. 3. A typical image of COSMO-SkyMed SAR.

Table 1. Ground truth data of soybean field (2010. 9. 13).

\begin{tabular}{|c|c|c|c|}
\hline \multirow{2}{*}{$9 / 13$} & \multicolumn{3}{|c|}{ Ground truth (soybean field) } \\
\hline & Parameters & Mean & Std dev. \\
\hline & Canopy height $(\mathrm{cm})$ & \multicolumn{2}{|c|}{85.07} \\
\hline \multirow{5}{*}{ Stem } & $\#$ of stem $\left(\mathrm{m}^{2}\right)$ & \multicolumn{2}{|c|}{12.85} \\
\hline & Water content $\left(\mathrm{g} / \mathrm{cm}^{3}\right)$ & \multicolumn{2}{|c|}{0.60} \\
\hline & Diameter $(\mathrm{cm})$ & 0.58 & 0.13 \\
\hline & Length $(\mathrm{cm})$ & 85.07 & 8.63 \\
\hline & Vert. angle (Deg) & 88.02 & 0.96 \\
\hline \multirow{5}{*}{ Branch } & $\#$ of branch $\left(\mathrm{m}^{2}\right)$ & \multicolumn{2}{|c|}{425.38} \\
\hline & Water content $\left(\mathrm{g} / \mathrm{cm}^{3}\right)$ & \multicolumn{2}{|c|}{0.68} \\
\hline & Diameter $(\mathrm{cm})$ & 0.15 & 0.05 \\
\hline & Length $(\mathrm{cm})$ & 23.89 & 9.07 \\
\hline & Vert. angle (Deg) & 56.22 & 7.99 \\
\hline \multirow{6}{*}{ Leaf } & $\#$ of leaf $\left(\mathrm{m}^{2}\right)$ & \multicolumn{2}{|c|}{903.10} \\
\hline & Water content $\left(\mathrm{g} / \mathrm{cm}^{3}\right)$ & \multicolumn{2}{|c|}{0.61} \\
\hline & Width $(\mathrm{cm})$ & 4.87 & 1.10 \\
\hline & Length $(\mathrm{cm})$ & 9.78 & 1.70 \\
\hline & Thickness $(\mathrm{cm})$ & \multicolumn{2}{|c|}{0.022} \\
\hline & Vert. angle (Deg) & 35.00 & 35.00 \\
\hline \multirow{6}{*}{ Soybean } & $\#$ of soybean $\left(\mathrm{m}^{2}\right)$ & \multicolumn{2}{|c|}{891.56} \\
\hline & Water content $\left(\mathrm{g} / \mathrm{cm}^{3}\right)$ & \multicolumn{2}{|c|}{0.70} \\
\hline & Depth $(\mathrm{cm})$ & 0.65 & 0.07 \\
\hline & Width $(\mathrm{cm})$ & 0.92 & 0.11 \\
\hline & Length $(\mathrm{cm})$ & 3.56 & 0.40 \\
\hline & Vert. angle (deg) & 40.00 & 5.00 \\
\hline \multirow{3}{*}{ Surface } & $\mathrm{Mv}\left(\mathrm{cm}^{3} / \mathrm{cm}^{3}\right)$ & \multicolumn{2}{|c|}{0.27} \\
\hline & RMS height (cm) & \multicolumn{2}{|c|}{2.01} \\
\hline & Correlation length $(\mathrm{cm})$ & \multicolumn{2}{|c|}{19.44} \\
\hline
\end{tabular}

model. Table 1 shows one of the ground truth data sets.

To reduce input parameters, probability density functions of stems and branches are combined together, because the effect of leaves is dominant compared with 


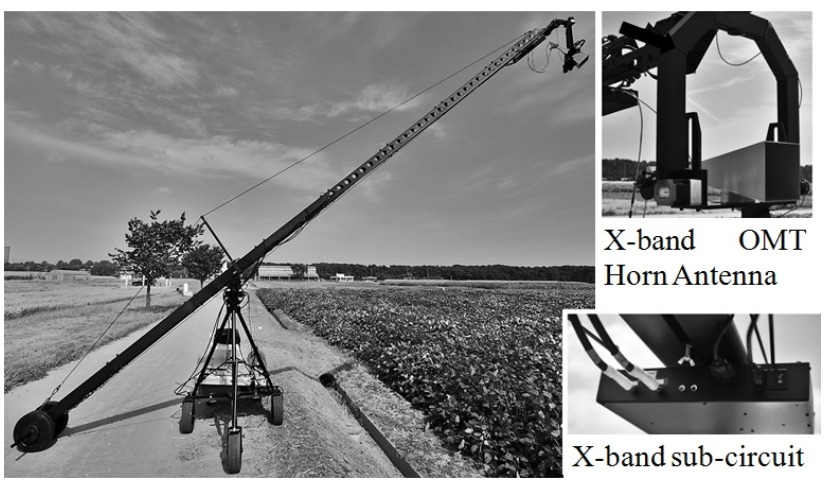

Fig. 4. Photograph of the scatterometer system.

stems, branches, and soybeans in the soybean field. In this case, the density of branches, stems, water contents, diameter, length, and vertical angle which have been used in the model are 438.23, $0.68 \mathrm{~g} / \mathrm{cm}^{3}, 0.16 \mathrm{~cm}$, $25.68 \mathrm{~cm}$, and 30 degree, respectively. We assume that the shape of a soybean is a circular cylinder. The soybean diameter is then replaced by $0.786 \mathrm{~cm}$ which is the mean value of the depth and width.

\section{Verification}

The 1st-order RTM is compared with COSMO-SkyMed temporal data and scatterometer angular data for verification. Figure 5 shows a comparison between the 1st-order RTM-based scattering model and the COSMO-SkyMed data of the soybean field with HH-polarization. The COSMO-SkyMed data have five points at 30 degrees and six points at 40 degrees, and RT simulation results are eleven datasets at 30 and 40 degrees, respectively. The measured backscattering coefficients increase steadily as the density of leaves increases. Backscattering coefficients saturate at 60 days after planting.

The backscattering coefficients increase as the number of soybean pods increase rapidly 70 days after planting. The backscattering coefficients decreased when most of the leaves had fallen 90 days after planting. Table 2 demonstrates the difference between measured and estimated backscattering coefficients. The estimated backscattering coefficients agree quite well with the SAR data. The average RMSE (Root Mean Square Error) is $0.163 \mathrm{~dB}$.

Fig. 6 shows the contributions of the five scattering mechanisms to the total radar backscatter for HH-polarizations at various days after planting. This figure shows the backscattering change at 40 degrees and the same tendency was shown for other angles. The ground scattering declined and direct vegetation scattering rose. Mechanisms 2, 3, and 4 give much lower backscatter than mechanisms 1 and 5, which means that the in

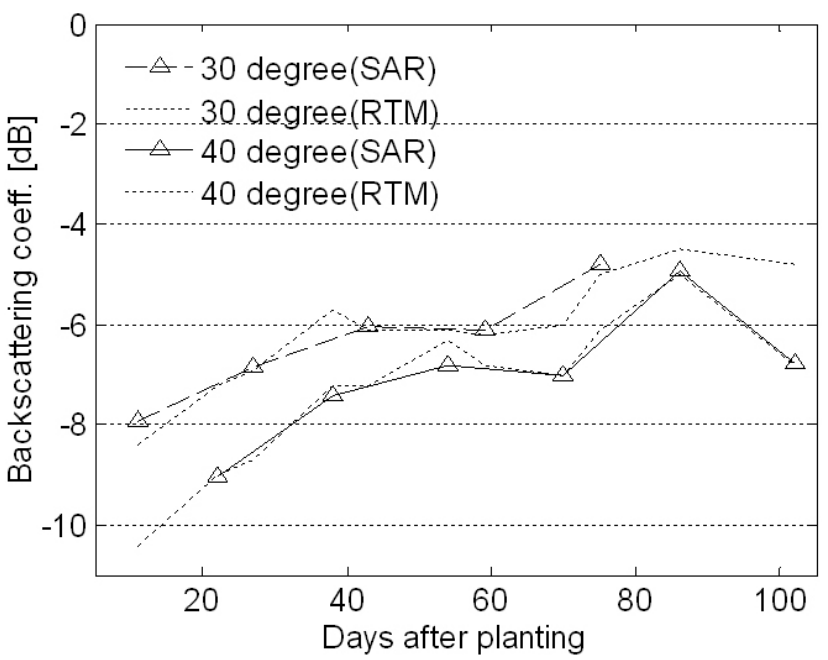

Fig. 5. Comparison between measured and estimated backscattering coefficients at $30^{\circ}$ and $40^{\circ}$ for the whole soybean growth period.

Table 2. Comparison between SAR and simulation results.

\begin{tabular}{|c|c|c|c|c|c|}
\hline 30 deg. & Sigma 0 & RTM & 40 deg. & Sigma 0 & RTM \\
\hline $7 / 10$ & -7.93 & -8.4 & $7 / 21$ & -9.04 & -9.0 \\
\hline $7 / 26$ & -6.84 & -6.9 & $8 / 6$ & -7.41 & -7.2 \\
\hline $8 / 11$ & -6.03 & -6.1 & $8 / 22$ & -6.83 & -6.3 \\
\hline $8 / 27$ & -6.10 & -6.2 & $9 / 7$ & -7.03 & -7.0 \\
\hline $9 / 12$ & -4.80 & -5.0 & $9 / 23$ & -4.93 & -5.0 \\
\hline & & & $10 / 9$ & -6.79 & -6.8 \\
\hline
\end{tabular}

teraction between vegetation and ground is negligible.

In this case, the three input parameters (number of soybeans, number of leaves and water contents of leafves)

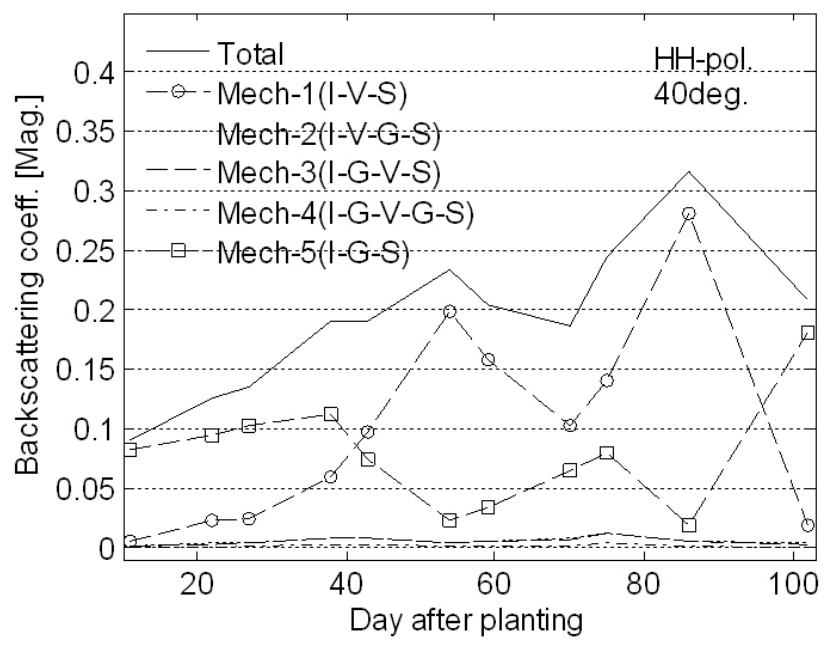

Fig. 6. Contributions of five scattering mechanisms to the total backscatter by day after planting. 


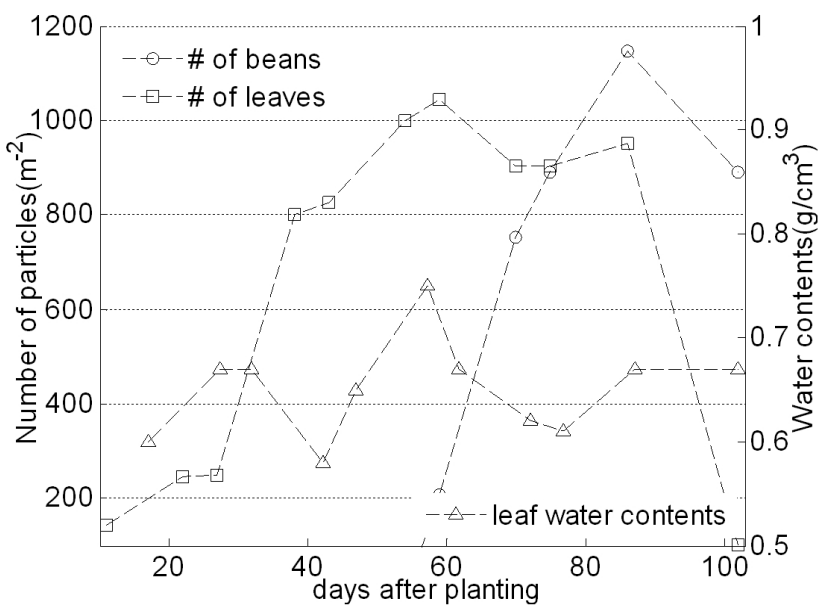

Fig. 7. The number of leaves, number of soybean pods, and water contents of leaves by days after planting.

are the most dominant parameters for vegetation scattering. Fig. 7 shows the sensitivity of three components at various days after planting. The number of leaves increased until 60 days after planting and then decreased rapidly after 90 days. However vegetation scattering decreased slightly after 55 days and rose again due to changes in leaf water content, as shown in Fig. 7. The growth of soybean pods also affected the vegetation scattering 70 days after planting. The soybean pods grew rapidly from 60 days after planting. Therefore, vegetation scattering is determined by a combination of these three parameters. The vegetation scattering can be computed using a simple regression curve in (11).

$$
\sigma^{0}=10 \log \left(w_{1} M w_{l}+w_{2} N_{l}+w_{3} N_{b n}-0.5\right)
$$

This equation represents the vegetation scattering fr-

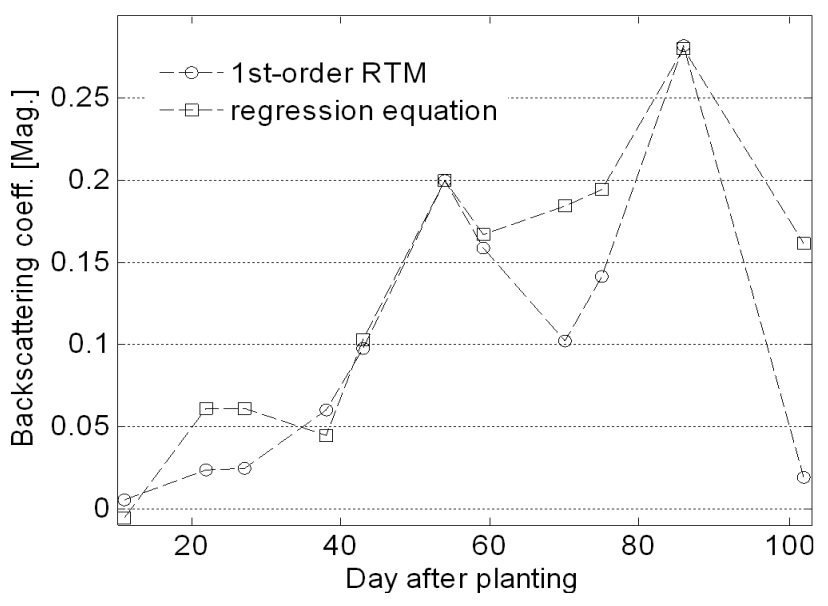

Fig. 8. Comparison between 1st-order RTM and regression equation for change of vegetation scattering by days after planting.

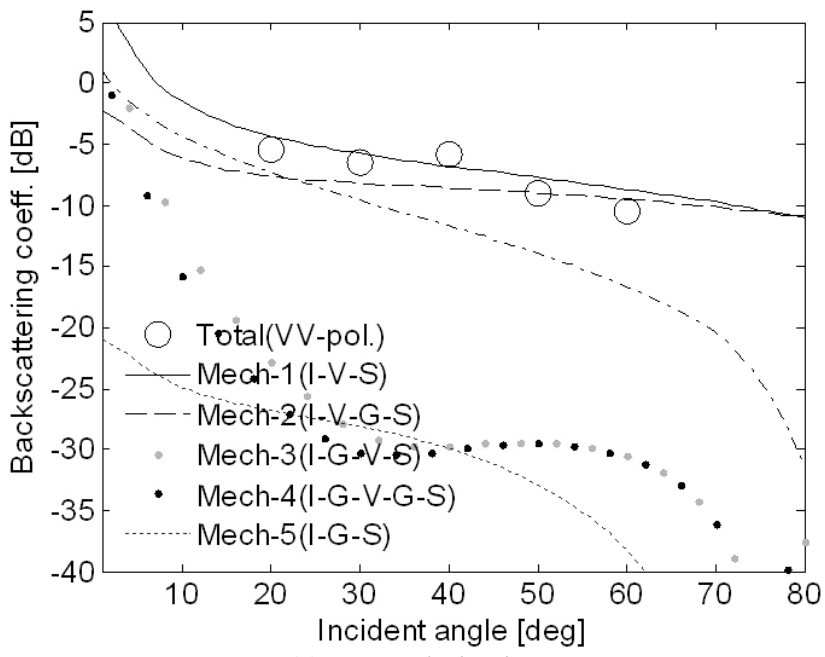

(a) VV-polarization

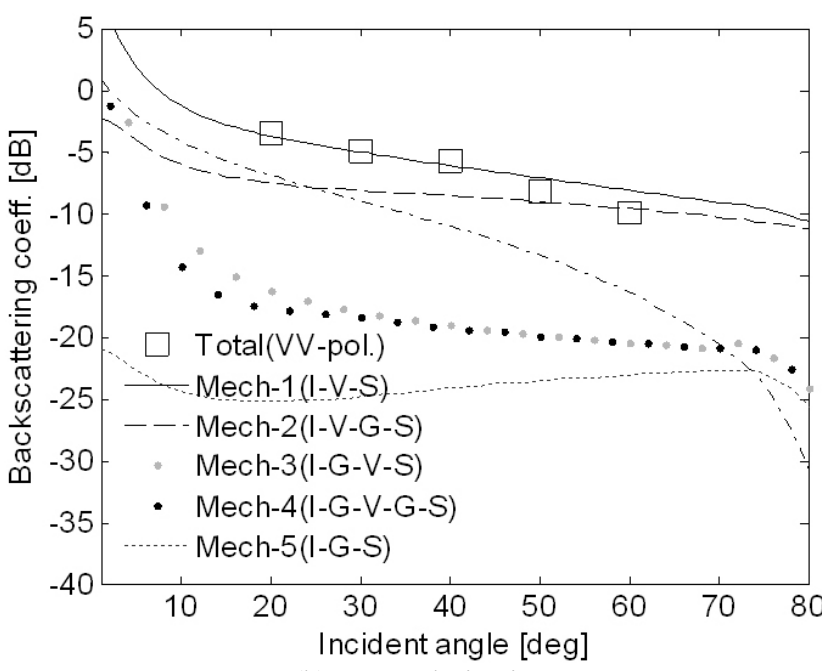

(b) HH-polarization

Fig. 9. Contributions of five scattering mechanisms to the total backscatter of 1st-order RTM and the scatterometer data.

om three components and weighting value $w_{1}, w_{2}, w_{3}$. We apply weighting value as $w_{1}=0.8, w_{2}=0.0001, w_{3}=$ 0.00013 . Fig. 8 shows the comparison between estimated vegetation scattering using 1st-order RTM and the simple regression equation.

Fig. 9 shows the comparison between the scatterometer measurements data and the 1st-order RTM results based on the contribution of the five scattering mechanisms to the total radar backscatter for VV-and $\mathrm{HH}$-polarization backscattering coefficients. The direct ground backscatter (mechanism-5) is dominant for low incidence angles, while the direct vegetation backscatter is dominant at large incidence angles. This means that the vegetation scattering increases as incidence angle increases because the attenuation from vegeta- 
tion layer increases. The degree of attenuation is generally proportional to the density of vegetation and water content.

\section{Conclusion}

We developed an accurate model of radar backscattering from a vegetation canopy by using the 1st-order RTM to compute the backscattering coefficients of a soybean field. The scattering model was validated by actual measurements of the backscattering coefficients using the ground-based Hongik Polarimetric Scatterometer (HPS) and the COSMO-SkyMed SAR. The results of the model simulation agree quite well with the measured backscattering coefficients.

The authors like to thank the Italian Space Agency (ASI) for providing COSMO-SkyMed SAR images (PI no. 2185). This work was supported by Midcareer Researcher Program through NRF Grant 20110000087 funded by the MEST of Korea.

\section{References}

[1] K. Sarabandi, "Monte Carlo simulation of scattering from a layer of vertical cylinders," IEEE Trans. Antennas Propag, vol. 41, no. 4, pp. 465-475, Apr.

Soon-Koo Kweon

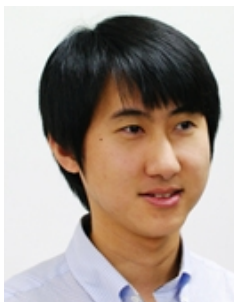

received the B.S. degree in electronic and electrical engineering and the M.S. degree in electronic information and communication engineering from Hongik University, Seoul, Korea, in 2007 and 2009, respectively. He is currently a Ph.D. candidate in the Department of Electronic Information and Communication Engineering, Hongik University, Seoul, Korea. His research interests include microwave scattering, microwave remote sensing, and SAR image analysis.
1993.

[2] Y. Oh, K. Sarabandi, and F. T. Ulaby, "An empirical model and an inversion technique for radar scattering from bare soil surfaces," IEEE Trans. Geosci. Remote Sensing, vol. 30, pp. 370-382, Mar. 1992.

[3] L. Tsang, J. A. Kong, and R. T. Shin, Theory of Microwave Remote Sensing, John Wiley and Sons, 1st edn, 1985.

[4] F. T. Ulaby, M. K. Moore, and A. K. Fung, Microwave Remote Sensing, Active and Passive, vol. 1, Artech House, Norwood, MA, USA, 1982.

[5] Y. Oh, K. Sarabandi, and F. T. Ulaby, "Semi-empirical model of the ensemble-averaged differential Mueller matrix for microwave backscattering from bare soil surfaces," IEEE Trans. Geosci. Remote Sensing, vol. 40, no. 6, pp. 1348-1355, Jun. 2002.

[6] Y. Oh, J. Y. Hong, "Re-examination of analytical models for microwave scattering from deciduous leaves," IET Microwaves, Antennas, Propag., vol. 1, no. 3, pp. 617-623, Jun. 2007.

[7] F. T. Ulaby, C. Elachi, Radar Polarimetry for Geoscience Applications, Artech House, Norwood, MA, USA, 1990.

[8] K. Sarabandi, Y. Oh, and F. T. Ulaby, "Measurement and calibration of differential Mueller Matrix of distributed targets," IEEE Trans. Antenna Propagat., vol. 40, pp. 1524-1532, Dec. 1992.

\section{Ji-Hwan Hwang}

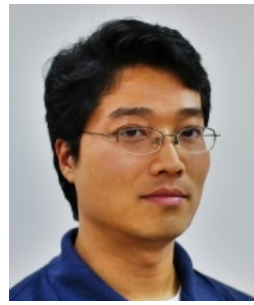

received the B.S. degree in radio engineering and the M.S. degree in radio science and communication engineering from Hongik University, Seoul, Korea, in 2001 and 2003, respectively. He worked at LG Electronics Co. from 2003 to 2006. He is currently a Ph.D. candidate in the Department of Electronic Information and Communication Engineering, Hongik University, Seoul, Korea. His research interests include microwave scattering, microwave remote sensing, and antennas. 
KWEON et al. : DEVELOPMENT OF A SCATTERING MODEL FOR SOYBEAN FIELDS AND VERIFICATION WITH $\cdots$

Yisok $\mathrm{Oh}$

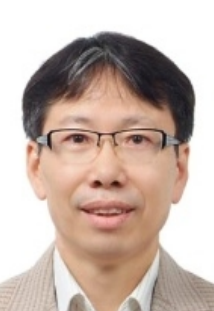

received the Ph.D. degree in electrical engineering from the University of Michigan, Ann Arbor, in 1993. Since 1994, he has been with the School of Electronic and Electrical Engineering, Hongik University, Seoul, Korea. Currently, he is a Professor at Hongik University, and an IEEE Fellow. His current research interests include microwave remote sensing, antennas, and radio wave propagation. 